\title{
Medical students from Parakou (Benin) and West-African traditional beliefs on death and cadavers
}

\author{
*Charlier P, Brun L, de la Grandmaison GL, Hervé C
}

1. Department of Forensic Medicine and Pathology, University Hospital R. Poincaré, Paris, France

2. Department of Pathology, University Hospital, Parakou, Benin

3. Department of Forensic Medicine and Pathology, University Hospital R. Poincaré Garches, France

4. Laboratory of Medical Ethics and Forensic Medicine, University of Paris, Paris, France

African Health Sciences 2012; (4): 443 - 445 http://dx.doi.org/10.4314/ahs.v12i4.7

\section{Introduction}

All physicians will be confronted one day to the death of one of their patients, but what is the position of traditional populations subject to modern medicine and ethic principles? ${ }^{1}$ Little is known about cultural beliefs related to death in Black Africa, and medical students attitudes towards working with human cadavers, for example at the occasion of anatomy courses or post-mortem examinations (dissections).

\section{Methods}

At the occasion of one-week intensive courses in medical anthropology in July 2011 (and research in ethics relative to the status of the human cadaver), we carried out a survey on a total of these 77 undergraduate students in their last-but-one $\left(5^{\text {th }}\right)$ year of medicine at the University of Parakou (60 males and 17 females, from 22 to 34 years old). All are Black African natives originating from Benin. The Faculty of Medicine of Parakou (the second one in the country), created in 2001, delivered 55 young physicians in 2011.

A one printed page questionnaire (designed collegially by all the authors and co-authors of this paper) was given to all of them at the extreme end of the courses, with a delay of 30 minutes for answering all the questions. No complementary interview was carried out with any medical student. All answered easily to this questionnaire, without any taboo.

*Corresponding author:
Philippe Charlier
Department of Forensic Medicine and Pathology
University Hospital R. Poincaré
104 R. Poincaré boulevard
92380 Garches
France
Tel. (33) 147107680
E-mail ph_charlier@yahoo.fr

African Health Sciences Vol 12 Issue 4 December 2012

\section{Results}

$87 \%$ of them $(n=67)$ consider that the dead body belongs to the family (versus a minority of them who considers it belongs to Mother Nature, God or the scientific community). For $87 \%$ of them ( $n=67)$, a dead body is a "sacred object", this position being based on religious beliefs rather than practical considerations for $80 \%$ of them $(n=62)$.

For $95 \%$ of these students, a dead body inspires respect $(n=73)$, the others being disgusted. $31 \%$ would be opposed to an autopsy of their direct relatives $(n=24)$, a position based on the delay in giving the cadaver back to the family $(25 \%, \mathrm{n}=19)$, the fragmentation of the body $(49 \%, \mathrm{n}=38)$, the absence of complete restoration of the corpse (45\%, $\mathrm{n}=35$ ), the feeling of profanation of the cadaver $(30 \%, \mathrm{n}=23)$, the alteration of the skin barrier $(5 \%$, $n=4)$, the alteration of the body's integrity $(22 \%$, $\mathrm{n}=17$ ), the fact that some organs will not be replaced in the cadaver after the autopsy for microscopy purposes $(52 \%, n=40)$, and the non-respect of traditional rules or local customs $(27 \%, \mathrm{n}=21)$. Autopsy was considered a profanation for $14 \%$ of them $(n=11)$, and a cadaver "vulnerable" for $47 \%$ $(n=36)$.

When asked if they would accept to delay by one month the inhumation of their relatives in order to take back all organs sampled for histological purposes, $62 \%(\mathrm{n}=48)$ agreed with this proposition. Lastly, 92\% $(n=71)$ considered modern embalming and/or formaldehyde-based conservation processes as not contra-natural.

\section{Discussion}

Such results are specific to a transitional population deep-rooted in traditional beliefs, with recent modern scientific (medical) and ethical incorporations. About one-third of these students are Christians by birth (from their parents), and another third are Muslims, thus less influenced by 
their Black West-African traditional culture. The weight of the habits remains however almost always present whatever the practiced religion. Such medicosocial aspects have to be known on both sides of the therapeutic process, and at the occasion of any patient's death.

Benin is indeed the original land of Voodoo, all (or most of all) deaths being considered suspect because related to magical practices against living individuals. Full respect towards cadavers is the rule, as they still have a more or less negative power against living individuals and/or the rest of the community.

The traditional position of sub-Saharan West-African communities toward death and dead bodies can be summed up as follows. ${ }^{6-10}$ There are three parts in Man: the body, in decomposition then putrefaction after death; the spirit, that stays on Earth (with deification by relics, for example); and the soul, that comes back to God (or the Gods). Death is thus a kind of birth in another world, as birth is a kind of death in another world. As a consequence, dead peoples are never entirely and truly dead, death being a kind of energy in deliquescence, in degradation, with positive and negative emanations; such beliefs explain the necessity of purification, when having any contact with or being close to a cadaver. One may then better understand this traditional opposition against any autopsy and/or delay for the return of the cadaver, perceived as a lack of respect to the memory and body of the dead individual. It is also an unnecessary degradation, as all deaths (or a majority of them) are unnatural (magic deaths caused by a sorcerer or a bad spell), the family or the group avenging the dead with religious or ritual practices. A hierarchy in deaths exists, especially in bad deaths, for example, premature deaths (children and young individuals) wandering on Earth till the time they should have normally been dead. So, rituals have been created by traditional communities in order to protect themselves, and force the soul to leave and join the 'other world'. The same with the death of a pregnant woman, this last one being disemboweled in order to extract the baby body, which is eliminated; the risk for the community with such gestational death is a magic epidemic of sudden death caused by the frustrated soul of the in-utero dead baby, and putative mother. Other pathological or accidental contexts exist, considered as a source of bad deaths: leprosy, madness, elephantiasis, incurable wound, suicide, soldier, skin diseases (smallpox, chickenpox, measles), and lightning. In this last case, the victim is magically 'waken up' just long enough to let him/her explain the reason for his/her supernatural death (i.e. cite the name of their murderer or the sorcerer at the origin of the event)...

Such data and beliefs have to be moderated: the fact that "all deaths are unnatural" or at least that death and/or disease could be produced facilitated or by magical means ${ }^{11-13}$ is not held in all sub-Saharan traditions, and not even in all ethnic and/or religious groups related to the "Bantu expansion" (for example in Southern and Eastern Africa). ${ }^{14-15}$ Our study involved populations related to Voodoo beliefs (principally the Ewe, Kabye, Mina, Fon, and Yoruba communities), ${ }^{16}$ excluding other "traditional" ones, such as Christianity from Ethiopia.

\section{Conclusion}

Such data are important for the respect of both medical students and relatives' sensibility towards dead patients in Benin (and reasonably in other subSaharan West-African countries). For example not to ask (or perform!) an autopsy if the family has opposed views based on religious beliefs.

Other ways exist in order to know the exact cause of death, allowing a respect of the cadaver's physical integrity and/or individual's post-mortem image, such as multiples biopsies for microscopic examination, ultra-focal body openings (microautopsies), post-mortem CT-scan (virtopsies), delay by one month the inhumation in order to take back all organs sampled for histological purposes, etc. Such data are important to know for improving the respect of medical ethics, especially during the training of health professionals with cadavers in subjects like anatomy in this region.

Even if professionally involved in the interest of post-mortem examinations, a non-negligible part of medical students would be opposed to an autopsy of their relatives (maybe because of the non full-respect of religious beliefs during such a scientific activity?). Within the next few years, a complementary qualitative approach, exploring the students experience, may provide more information about what this data add to the medical teaching, and changed the vision of the dead body's status.

We declare that we have no conflict of interest related to the subject of this article.

\section{Acknowledgments}

To miss Veronique Huynh for English proofreading; to professor David Kofi Aza for providing 
data dealing with African traditional beliefs; and to the three anonymous reviewers for their important comments on the whole article.

\section{References}

1. Nnodim JO, Osuji CU. Comparison of medical and non-medical student attitudes to social issues in medicine. Med Educ 1995; 29(4): 273-7.

2. Aujoulat I, Johnson C, Zinsou C, Guédénon A, Portaels F. Psychosocial aspects of health seeking behaviours of patients with Buruli ulcer in southern Benin. Trop Med Int Health 2003; 8(8): 750-9.

3. Gomes do Espirito Santo E, Floury B, Cissé M. Déterminants du recours aux soins dans la ville de Cotonou (Bénin). Bull World Health Organ 1998; 76(2): 195-201.

4. Omonzejele PF. African concepts of health, disease, and treatment: an ethical enquiry. Explore (NY) 2008; 4(2): 120-6.

5. Omonzejele PF. Current ethical and other problems in the practice of African traditional medicine. Med Law 2003; 22(1): 29-38.

6. Kale SS. Perspectives on spiritual care at Hospice Africa Uganda. Int J Palliat Nurs 2011; 17(4): 177-82.

7. Omonzejele PF, Maduka C. Metaphysical and value underpinnings of traditional medicine in
West Africa. Chin J Integr Med 2011; 17(2): 99104

8. Denham AR, Adongo PB, Freydberg N, Hodgson A. Chasing spirits: clarifying the spirit child phenomenon and infanticide in Northern Ghana. Soc Sci Med 2010; 71(3): 608-15.

9. Wilson KH. Medicine's missing dimension. Trans Am Clin Climatol Assoc 2010; 121: 309-17.

10. Hewlett BL, Hewlett BS. Providing care and facing death: nursing during Ebola outbreaks in central Africa. J Transcult Nurs 2005; 16(4): 289-97.

11. Mathis JL. A sophisticated version of voodoo death. Psychosomat Med 1964; 26(2): 104-107.

12. Sargant W. Witch doctoring, zar and voodoo: their relation to modern psychiatric treatments. Proc R Soc Med 1967; 60: 1055-1062.

13. Prudent N, Johnson P, Carroll J, Culpepper L. Attention-deficit/Hyperactivity disorder: presentation and management in the Haitian American child. Prim Care Companion J Clin Psychiatry 2005; 7(4): 190-197.

14. Ehret C. Bantu expansions: re-envisioning a central problem of early African history. Int $J$ Afr Hist Studies 2001; 1(34): 5-41.

15. Oliver R. The problem of the Bantu expansion. J Afr Hist 1966; 7(3): 361-376.

16. Passot B. Le Bénin. Les hommes et leur milieu, guide pratique. Paris: L'Harmattan; 1996. 